\title{
Implantação de ferrovias de alta velocidade: contribuição metodológica para o gerenciamento ambiental de obras lineares em áreas contaminadas e potencialmente contaminadas
}

\author{
Fabiana Alves Cagnon ${ }^{1}$, Marne Lieggio Junior ${ }^{2}$, Carlos Frederico de Castro Alves ${ }^{3}$. \\ Augusto de Oliveira Barbosa ${ }^{4}$ e Mariana Guarnier Fagundes ${ }^{5}$
}

\begin{abstract}
Resumo: O objetivo deste trabalho é propor um método de gerenciamento ambiental de obras lineares, tal como ferrovias de alta velocidade, nos trechos em que o traçado intercepta áreas contaminadas (AC), potencialmente contaminadas (AP) ou suspeitas de contaminação (AS). O estudo de caso utilizou o método proposto durante avaliação ambiental preliminar para a futura implantação do trem de alta velocidade entre Rio de Janeiro e Campinas (TAV). O método consiste na execução das seguintes etapas de trabalho: (a) identificação e caracterização de AP, AC e AS ao longo do traçado; (b) classificação dos trechos de obra; (c) elaboração de modelos conceituais de contaminação; (d) identificação de cenários e respectivas implicações ambientais sobre as obras e (e) proposição de ações ambientais. As ações de gerenciamento ambiental propostas para a fase de obras tiveram como objetivos minimizar impactos ambientais e possibilitar a implementação da obra com segurança para os trabalhadores no que diz respeito ao tema "áreas contaminadas". Adicionalmente, a estratégia proposta deverá contribuir para evitar eventuais atrasos na emissão de licenças ambientais e aumento nos custos do empreendimento.
\end{abstract}

Palavras-chave: ferrovia de alta velocidade; obra linear, área contaminada; gerenciamento ambiental; modelo conceitual de contaminação; impacto ambiental; risco à saúde.

\begin{abstract}
The objective of this study is to propose a methodology to the environmental management of linear civil works (such as high-speed railways) in sections where the route intersects contaminated, potentially contaminated or suspected contaminated areas. The case study used the proposed method for the Preliminary Environmental Site Assessment for the future deployment of high-speed train between Rio de Janeiro and Campinas (TAV). The method consists in performing the following work steps: (a) to identify and characterize contaminated, potentially contaminated and suspected contaminated sites; (b) to classify the sections of the route, c) to elaborate the conceptual models of contamination; (d) to identify the scenarios and the environmental implications to the civil works and e) to propose environmental management actions. The environmental management actions proposed by the study had as objectives to minimize the environmental impacts and to guarantee the health safety to the construction workers when considering contaminated sites. Additionally, the proposed strategy should help to prevent any delays in issuing environmental permits and increased development costs.
\end{abstract}

Keywords: high-speed railway; linear civil work; contaminated areas; environmental management; conceptual model of the contamination; environmental impact; health risk.

\section{INTRODUÇÃO}

A construção de obras lineares, tais como ferrovias, dutos e rodovias, implica necessariamente na interferência com solos e, por vezes, com águas subterrâneas que podem apresentar significativa contaminação em decorrência de atividades que ocorreram no local ou em sua circunvizinhança. Entre os potenciais impactos ambientais decorrentes da execução de obras em uma área contaminada são destaques a possibilidade de contaminação de outros locais por descarte inadequado de solo e água subterrânea contaminados removidos da obra e a ampliação da contaminação existente. Adicionalmente, existe ainda o risco à saúde dos trabalhadores das obras por manipulação de materiais contaminados.

\footnotetext{
${ }^{1}$ Fabiana Alves Cagnon, R\&C Projetos em Geologia Ltda

(fa.cagnon@uol.com.br)

2 Marne Lieggio Junior, Agência Nacional de Transportes Terrestres -

ANTT. (marnejr@gmail.com)

${ }^{3}$ Carlos Frederico de Castro Alves, Regea - Geologia e Estudos

Ambientais Ltda. (carlos_regea@yahoo.com.br)

${ }^{4}$ Augusto de Oliveira Barbosa, Regea - Geologia e Estudos Ambientais

Ltda. (augusto@regea.com.br)

${ }^{5}$ Mariana Guarnier Fagundes, Regea - Geologia e Estudos Ambientais

Ltda. (marianaf@regea.com.br)

Manuscrito recebido em 04/11/2013 e aprovado para publicação em $11 / 06 / 2015$.

Este artigo é parte de TRANSPORTES v. 23, n. 2, 2015. ISSN: 2237-1346

(online). DOI:10.4237/transportes.v23i1.746
}

Dessa forma, é fundamental que os gestores da obra, governamentais ou não, se valham de métodos capazes de identificar os potenciais impactos, os riscos e as implicações desse cenário sobre a obra.

A aplicação de uma estratégia de gerenciamento que compreende a prévia identificação e caracterização das áreas contaminadas ao longo do traçado permite a definição prévia de ações necessárias para minimizar e/ou evitar impactos e riscos, além de poder melhor subsidiar a definição de traçados definitivos de empreendimentos lineares e evitar aumento de prazos e de custos de investimento durante a sua implantação.

$\mathrm{Na}$ literatura nacional e internacional, o tema ora apresentado é bastante escasso, não havendo referências específicas ou uma metodologia consagrada que contemple o gerenciamento de obras lineares em meios contaminados.

De acordo com SANTOS (2012), de maneira geral as práticas de gerenciamento de áreas contaminadas em obras de metrô em diversos países é feita por meio da implementação de ações de controle nos projeto, sem uma sistematização. Neste contexto é importante destacar que obras para implementação de metrô são uma daquelas de maior interferência em áreas com solo contaminado, visto que são prioritariamente subterrâneas. A exemplo disso, a agência ambiental americana propõe por meio do documento USEPA (2001) restrições para a disposição de solo contaminado em 
aterro e dá diretrizes para isso com base na qualidade do solo e nas características das áreas de disposição.

De acordo com SÁNCHEZ (1998), nos Estados Unidos, na Europa e em outros locais, os debates públicos e a legislação relacionada à poluição historicamente seguiram a seguinte ordem: águas superficiais, qualidade do ar e poluição dos solos. De acordo com CETESB (2001), da mesma forma ocorreu no Brasil e, em especial, no Estado de São Paulo.

Por meio de pesquisa bibliográfica é possível constatar que, o tema contaminação de solos e águas subterrâneas é relativamente recente até mesmo em países desenvolvidos e precursores de leis a esse respeito. Outra constatação que se pode fazer é que a maioria das diretrizes, leis e normas relacionadas ao tema dizem respeito à gestão do passivo ambiental, tendo como foco a reabilitação do meio para uso seguro e não a gestão de obra quando esta intercepta uma área contaminada.

No Brasil, até a década de 90, as leis existentes tratavam a questão de contaminação dos solos e águas subterrâneas de forma genérica. A partir daí, em especial, com a publicação do Manual de Gerenciamento de Áreas Contaminadas de autoria da CETESB, em 1999, o tema passou a ser abordado de forma específica, entretanto, sempre dentro do contexto de "gestão de passivo ambiental". No Estado de São Paulo a publicação da Lei Estadual 13.577 em 2009 foi um marco importante no gerenciamento de áreas contaminadas, pois prevê instrumentos integrados para a prevenção da contaminação e para a remediação dessas áreas. No cenário nacional o principal marco foi a publicação da Resolução CONAMA 420 em 2009 que, assim como a citada lei do Estado de São Paulo, estabelece diretrizes para o gerenciamento de áreas contaminadas. De acordo com Mattiaso (2010), essa resolução foi um grande avanço para a gestão ambiental no Brasil e ajudará na prevenção e no tratamento das consequências dos impactos ambientais.

Os estudos envolvendo metodologia de gestão ambiental de obras em áreas contaminadas limitam-se a apresentar o tratamento dos materiais contaminados extraídos da obra, visando o atendimento à leis, normas e exigências realizadas pelos órgãos ambientais na emissão das licenças. Não há uma estratégia de gerenciamento ambiental específica e sistematizada, embasada no levantamento prévio de informações, que permitam elaborar cenários potenciais ou propor medidas eficazes para o gerenciamento de todas as etapas das obras.

Neste contexto, o objetivo deste trabalho é propor um método inovador e eficaz de gerenciamento ambiental para a implantação de obras lineares de infraestrutura de transportes, nos trechos em que o traçado intercepta áreas contaminadas, que permite reduzir impactos ambientais e eliminar potenciais riscos à saúde dos trabalhadores de forma sistematizada.

O método foi empregado pelos autores no estudo ambiental preliminar para implantação do TAV (Trem de Alta Velocidade Rio de Janeiro - Campinas) e, portanto, utilizase neste artigo como estudo de caso.

\section{PRINCIPAIS CONCEITOS RELACIONADOS A ÁREAS CONTAMINADAS}

De acordo com as definições adotadas pela REGEA (2012) e LIEGGIO Jr. et al (2012) merecem destaque os seguintes termos:

- Área Contaminada - AC: área, terreno, local, instalação, edificação ou benfeitoria que contenha quantidades ou concentrações de matéria em condições que causem ou possam causar danos à saúde humana, ao meio ambiente ou a outro bem a proteger (Decreto Estadual 59.263 de 05.06.13).

- Área Potencialmente Contaminada - AP: área, terreno, local, instalação, edificação ou benfeitoria onde são ou foram desenvolvidas atividades que, por suas características, possam acumular quantidades ou concentrações de matéria em condições que a tornem contaminada (Decreto Estadual 59.263 de 05.06.13).

- Área Diretamente Afetada - ADA: área onde efetivamente será instalado o empreendimento e as áreas de apoio (REGEA, 2012).

- Área de Influência Direta - AID: faixa que se estende desde o limite da ADA a até $300 \mathrm{~m}$ para cada lado do eixo central do percurso do TAV. Ou seja, a AID não inclui a ADA. Dessa maneira, o limite da AID corresponde à distância até a qual situações preexistentes de contaminação podem afetar a qualidade dos solos e águas subterrâneas na área de intervenção para a construção do TAV (REGEA, 2012).

- Área de estudo: traçado referencial, acrescido da ADA e da AID (REGEA, 2012).

- Área Suspeita de Contaminação - AS: área na qual, após a realização de uma avaliação preliminar, foram observadas indicações que induzem a suspeitar da presença de contaminação (CETESB, 2007).

- Modelo Conceitual de Contaminação: representação escrita ou gráfica de um sistema ambiental, e os processos biológicos, químicos e físicos, que determinam o transporte dos contaminantes a partir das fontes, através dos meios, até os receptores envolvidos (ABNT, 2013).

\section{TAV - TREM DE ALTA VELOCIDADE}

O traçado referencial do TAV vai da cidade do Rio de Janeiro, RJ até a cidade de Campinas no Estado de São Paulo, tem 510,8 km de extensão e atravessará 38 municípios; sendo 23 no Estado de São Paulo e 15 no Estado do Rio de Janeiro. Dos 38 municípios, 11 deles são atravessados entre $20 \mathrm{~km}$ e $30 \mathrm{~km}$ de suas extensões territoriais, 9 deles entre $10 \mathrm{~km}$ e $20 \mathrm{~km}$ e 18 deles, entre $2 \mathrm{~km}$ até $10 \mathrm{~km}$ (REGEA, 2012). A Figura 1 abaixo apresenta a localização do traçado, os limites desses municípios e as 35 AC e 859 AP identificadas.

\section{MÉTODO DE GESTÃO AMBIENTAL DE OBRA EM ÁREAS CONTAMINADAS}

O método propõe a condução de cinco etapas principais. Essas etapas estão descritas a seguir considerando os estudos realizados para a implantação do TAV. 


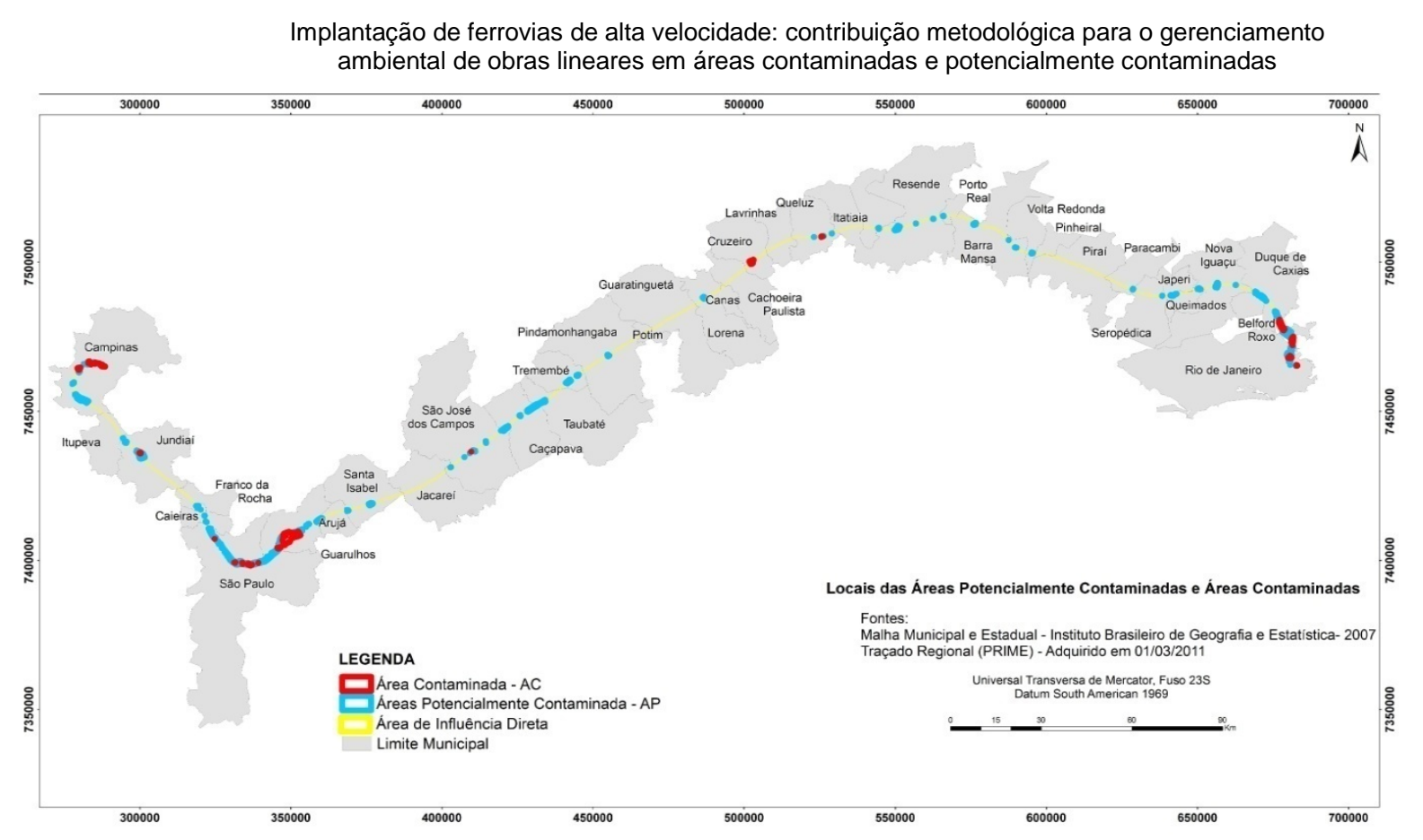

Figura 1. Localização da AID, AC e AP para o traçado referencial do TAV Rio de Janeiro - Campinas. Fonte: REGEA (2012).

\subsection{Identificação e caracterização de AC, AP e AS}

Como parte dos estudos ambientais prévios para implantação do TAV foi conduzida a identificação de todas as áreas contaminadas (AC), potencialmente contaminadas (AP) e suspeitas de contaminação (AS) localizadas na AID empregando-se o método proposto por REGEA (2012), que inclui as seguintes atividades:

1. Definição da Área Diretamente Afetada - ADA;

2. Definição da Área de Influência Direta - AID;

3. Delimitação dos trechos críticos;

4. Levantamento multitemporal do uso e ocupação do solo;

5. Identificação e caracterização de todas as AC, AP e AS e do tipo de obra por trecho: obra em superfície, obra em túnel ou viaduto;

6. Elaboração de banco de dados e fichas de cadastro e

7. Poligonização e georreferenciamento das áreas identificadas.

Os dados a respeito da obra, incluindo traçado referencial, imagens de satélite e métodos construtivos utilizados foram obtidos em PRIME (2008) e ANTT (2012).

De acordo com REGEA (2012), foram identificadas ao longo do traçado 36 ACs das quais 16 localizam-se no município de São Paulo, 10 em Campinas, 4 na cidade do Rio de Janeiro, 2 em Guarulhos e 1 área em cada uma das cidades de Cruzeiro, Jundiaí, Queluz e São José dos Campos. Além das áreas contaminadas, também foram identificadas 859 APs, que afetam 133 dos 510 km do traçado referencial. Os produtos com potencial de contaminação mais frequentes são os combustíveis líquidos e solventes aromáticos. As fontes de contaminação, em sua maior parte, provém de manutenção, armazenamento e disposição desses materiais. Dentre os potenciais contaminantes destacam-se os compostos orgânicos voláteis e semi voláteis e os metais.

Os trechos com AP e AC interceptando a ADA totalizam $50 \mathrm{~km}$ e os trechos com AC e AP, localizados exclusivamente na AID totalizam $83 \mathrm{~km}$. De acordo com REGEA
(2012) foi identificada a distribuição das ACs e APs por trecho de obra, ou seja, quais dessas áreas localizam-se em trechos de obra em superfície, em viaduto ou trechos de obra subterrânea.

\subsection{Classificação dos trechos de obra}

De acordo com REGEA (2012), os trechos da obra do TAV Rio de Janeiro - Campinas foram classificados em função da presença de AC e/ou AP e do tipo de obra a ser executada (superfície, viaduto ou túnel). Desta forma, foram identificados os seguintes tipos:

- Tipo A1: trecho com AC e obra em superfície;

- Tipo A2: trecho com AC e obra em viaduto;

- Tipo A3: trecho com AC e obra em túnel;

- Tipo B1: trecho com AP e obra em superfície;

- Tipo B2: trecho com AP e obra em viaduto;

- Tipo B3: trecho com AP e obra em túnel;

- Tipo C1: trecho sem áreas com potencial de contaminação e obra em superfície;

- Tipo C2: trecho sem áreas com potencial de contaminação e obra em viaduto; e

- Tipo C3: trecho sem áreas com potencial de contaminação e obra em túnel.

\subsection{Modelos conceituais de contaminação}

Com base na caracterização do meio físico e no histórico das atividades com potencial de contaminação desenvolvidas em cada uma das AC e AP foram elaborados os modelos conceituais de contaminação, os quais incluem a identificação das fontes de contaminação, das vias de transporte e dos receptores.

Para o estudo desenvolvido no TAV foram elaborados modelos conceituais de contaminação para grupos de áreas (AC/AP), definidos com base nos critérios apresentados a seguir, cuja premissa foi reunir áreas com similaridades e para as quais o modelo conceitual de contaminação fosse o mesmo:

- Uso da área e atividades desenvolvidas,

- Situação legal: áreas a serem desapropriadas ou não, 
- Potencial de contaminação das atividades desenvolvidas nessas áreas.

As implicações sobre uma obra executada em área contaminada depende fundamentalmente do modelo conceitual de contaminação, ou seja, das características da fonte de contaminação, das vias de transporte do contaminantes e dos receptores. Neste contexto, foram identificadas as implicações sobre a obra e, por sua vez, propostas as ações de gerenciamento para cada grupo de áreas para as quais um único modelo conceitual foi concebido.

Assim sendo, foram identificados os seguintes grupos:

- Grupos 1 e 2: áreas desapropriadas localizadas na ADA de usos diversos e para as quais será avaliada a presença de um extenso grupo de substâncias de interesse. Solo e a água subterrânea são vias de transporte e os receptores são os trabalhadores civis de várias etapas da obra. O grupo 1 possui AC e o grupo 2, AP. Esses grupos são tratados distintamente no que dizem respeito as ações de gerenciamento propostas. Para o grupo 1 recomenda-se a continuidade dos estudos de investigação ambiental com o objetivo de detalhar a situação de contaminação enquanto que, para o grupo 2, os estudos têm como objetivo confirmar ou não a contaminação potencial.

- Grupos 3 e 4: AP e AC com atividades comerciais de variados setores tais como postos de combustíveis, curtumes, processamento de minerais não metálicos, marcenaria, farmácia, aeroportos, estações ferroviárias e rodoviárias, pátio de manobra de trens, estações de tratamento de esgoto (ETE), aterros e unidades industriais do tipo alimentícia, têxtil, refinarias, metalúrgica/siderúrgica e papel e celulose. Esses grupos foram, cada um deles, subdivididos em 20 subgrupos para os quais foram identificadas as principais substâncias de interesse que podem causar danos à saúde e ao meio ambiente. Dentre os compostos de interesse relacionados foram identificados os compostos orgânicos voláteis (VOC) e semi voláteis (SVOC) e os hidrocarbonetos derivados de petróleo (TPH). Os compostos derivados de petróleo são, em sua maioria, tóxicos à saúde humana e ao meio ambiente, podendo causar diversos tipos de doenças, inclusive o câncer. Para esse grupo também solo e água subterrânea foram considerados como vias de transporte, e os receptores são os trabalhadores das obras. A diferença entre os grupos 3 e 4 são as ações ambientais propostas. O grupo 3 inclui áreas com potencial de contaminação localizadas a montante da obra do TAV e cuja estratégia de ação propõe a instalação de poços sentinelas localizados entre as áreas e a obra, enquanto que o grupo 4 é formado por áreas nas quais serão conduzidas vistoria e investigação confirmatória.

- Grupo 5: AP nas quais as investigações ambientais já realizadas não indicaram a presença de contaminantes e que, portanto, não são recomendadas ações de gerenciamento ambiental específicas.

O fluxograma da Figura 2 apresenta a estratégia para composição dos grupos.

\subsection{Cenários Potenciais de Contaminação e Implicações sobre a obra}

A definição das implicações sobre a obra considerou também a forma como os materiais potencialmente contaminados serão manuseados e entrarão em contato com os trabalhadores, complementarmente à utilização dos mode-

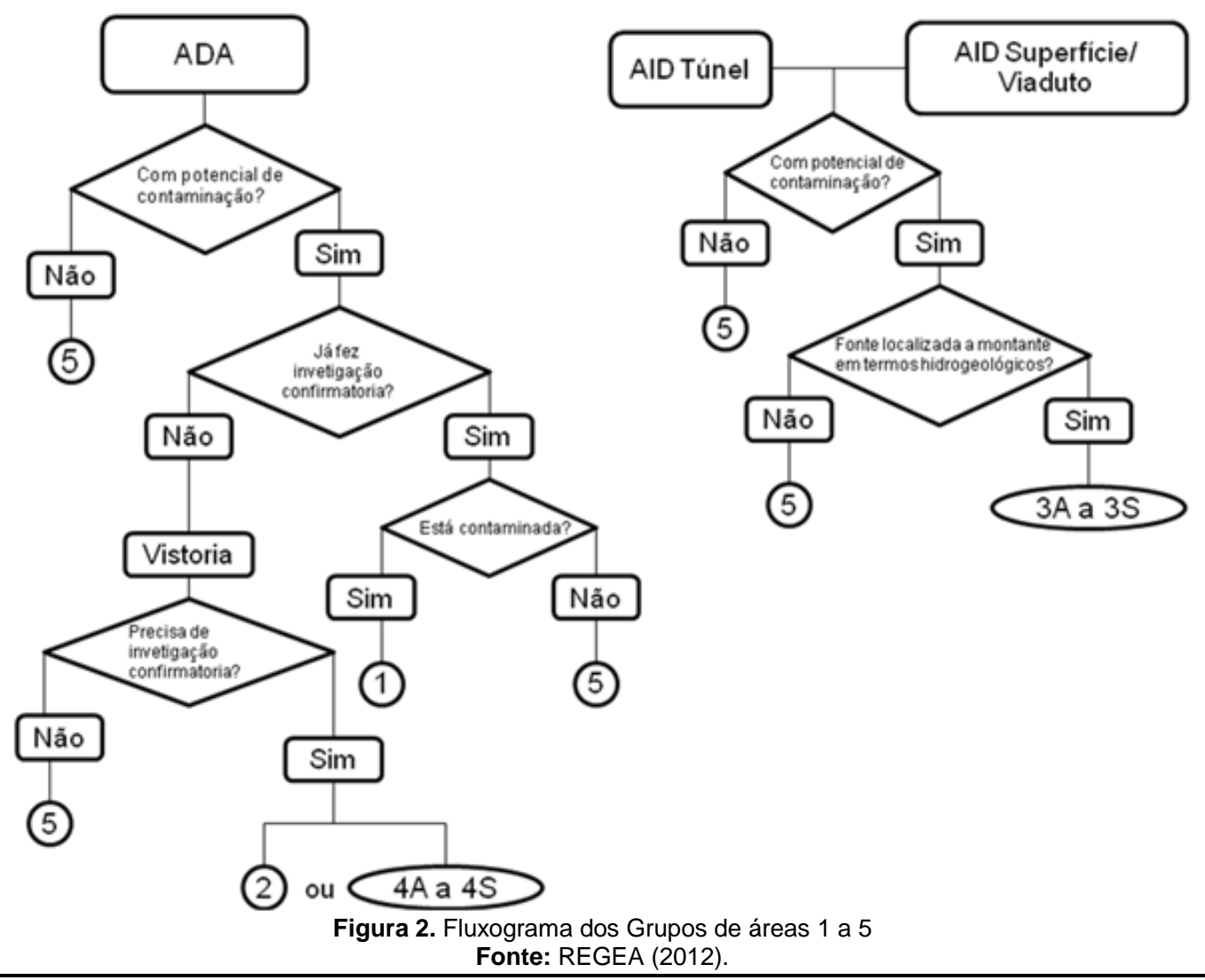




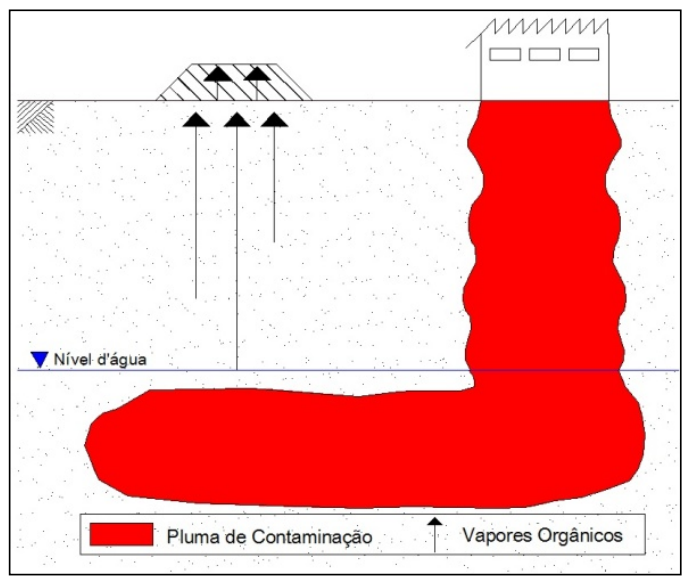

(a) Cenário 1 - Aterro com fonte em AID.

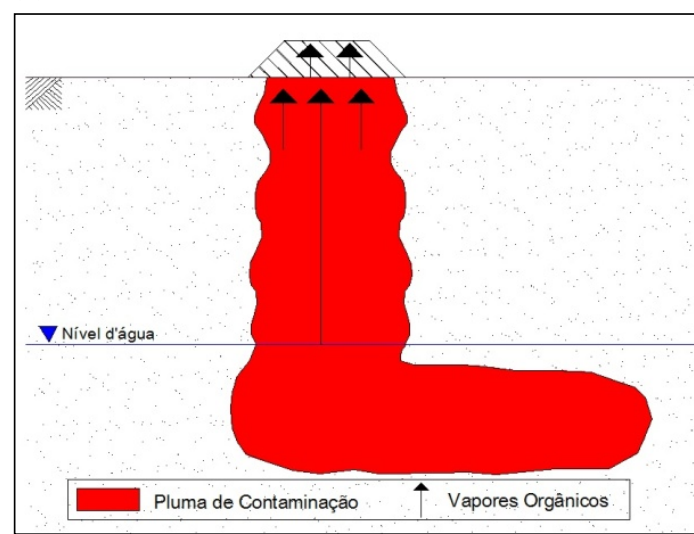

(c) Cenário 3 - Aterro com fonte em ADA.

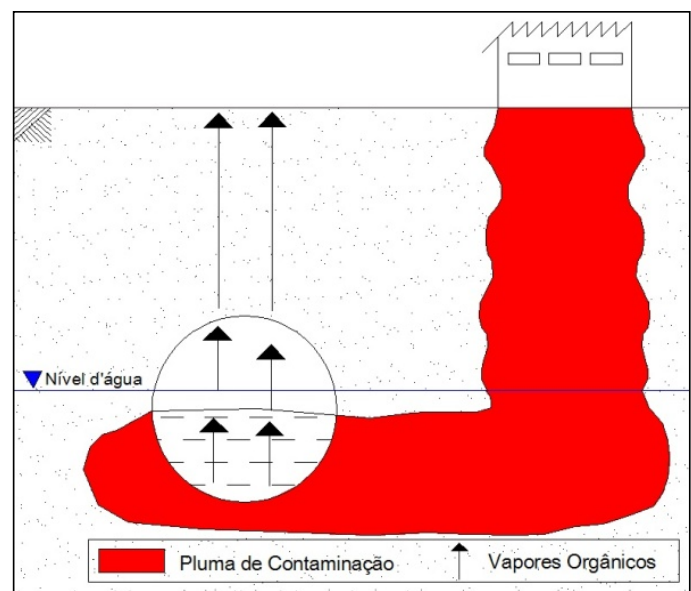

(e) Cenário 5 - Túnel com fonte em AID.

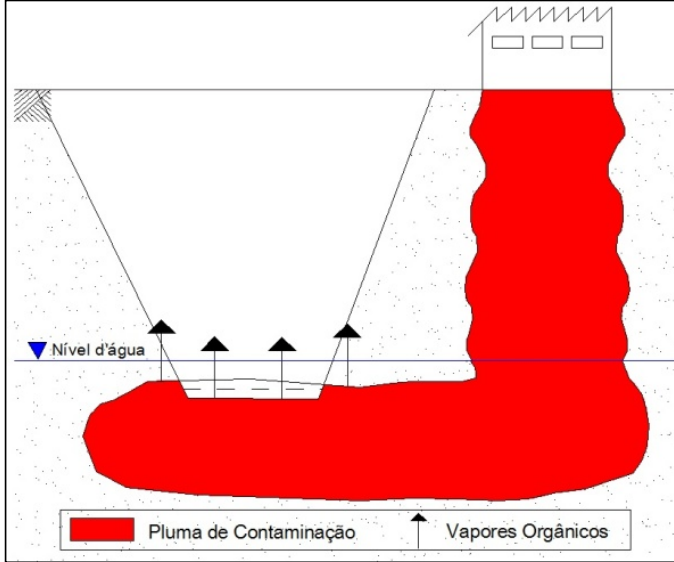

(b) Cenário 2 - Corte com fonte em AID.

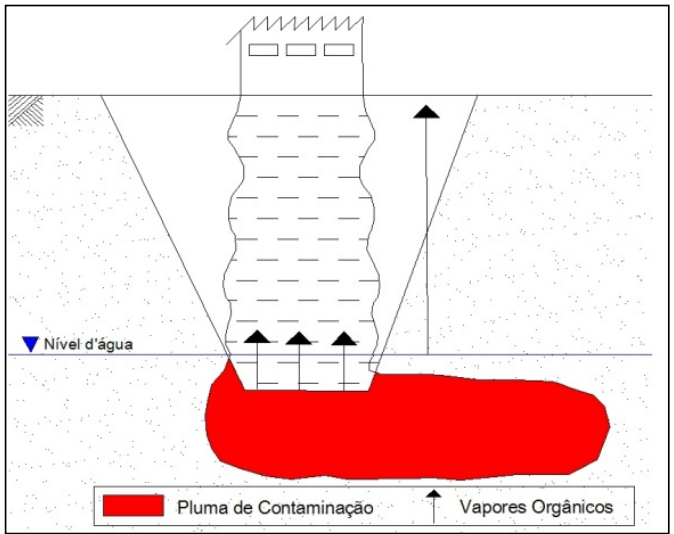

(d) Cenário 4 - Corte com fonte em ADA.

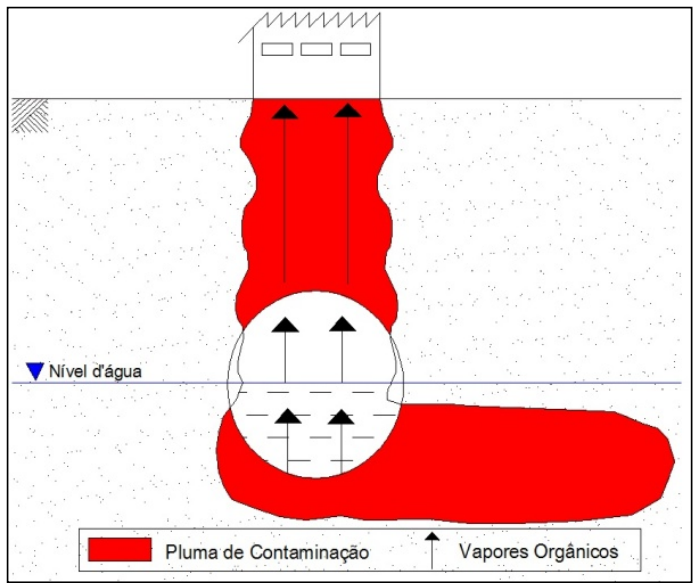

(f) Cenário 6 - Túnel com fonte em ADA.

Figura 3. Principais cenários potenciais de obras do TAV.

Fonte: REGEA (2012).

los conceituais de contaminação. Para tanto, foram consideradas as características das AC e AP e o tipo de intercepção dos meios afetados (solo e/ou água subterrânea) pela obra. A avaliação a respeito do tipo de intercepção foi feita considerando a tipologia de obra: se em viaduto, em superfície ou em túnel.

Para que fosse possível prever tais implicações foram elaborados "cenários potencias de obra” para os quais foram identificados os possíveis impactos a eles associados e os riscos potencias à saúde dos trabalhadores.

A elaboração dos "cenários potenciais de obra” considerou os seguintes aspectos:

- $1^{\mathrm{a}}$ - Classe do trecho: cada trecho do traçado referencial foi classificado conforme a qualidade do meio afetado (contaminado, potencialmente contaminado e sem indício de contaminação) e o tipo de obra (viaduto, superfície e túnel). São eles: A1, A2, A3, B1, B2, B3, C1, C2 e C3.

- $2^{\mathrm{a}}$ - Situação legal: (a) áreas desapropriadas e (b) não desapropriadas. São áreas desapropriadas todas as áreas localizadas dentro da ADA. Todas as demais áreas são áreas não desapropriadas.

- $3^{\text {a }}$ - Tipologia de obra: (a) Túneis: inclui todas as obras executadas exclusivamente enterradas. (b) Superfície: foi dividida em trechos com atividade apenas de aterro e com corte e aterro e (c) Viadutos: inclui todo o trecho de obra efetivamente em viaduto na faixa de desapropriação. 
CAGNON, F.A.; JUNIOR, M.L.; ALVES, F.C.; BARBOSA, A.O.; FAGUNDES, M.G.

Tabela1. Implicações sobre as obras de implantação do TAV Rio de Janeiro - Campinas. Fonte: REGEA (2012).)

\begin{tabular}{ll}
\hline Código & Implicações sobre a obra \\
\hline [ 1 ] & Riscos para a saúde do trabalhador por inalação de vapores e/ou risco de explosão. \\
[ 2 ] & Riscos para a saúde do trabalhador por inalação de partículas. \\
[ 3 ] & Riscos para a saúde do trabalhador por contato dérmico com solo e/ou água contaminada. \\
[ 4 ] & Riscos para a saúde do trabalhador por ingestão acidental de solo e/ou água subterrânea contaminada. \\
[ 5 ] & Contaminação ambiental devido à destinação incorreta de solos escavados contaminados \\
[ 6 ] & Contaminação ambiental devido à destinação incorreta de águas subterrâneas contaminadas bombeadas.
\end{tabular}

- $4^{a}$ - Localização da área em relação ao traçado: cada uma da AP ou AC foi localizada em relação ao traçado e agrupadas em: (a) nos trechos de obras em superfície e viaduto as AP e AC foram agrupadas em relação a ADA ou AID e (b) nos trechos de obra em túnel as AP e AC foram agrupadas em "áreas que interceptam o traçado" e "áreas que não interceptam o traçado".

- $5^{\text {a }}$ - Tipo de contaminantes: (a) Compostos orgânicos e (b) Compostos inorgânicos.

- $6^{\text {a }}$ - Meio potencialmente afetado: (a) Solo (zona não saturada) e (b) Água subterrânea (zona saturada).

A Figura 3 apresenta os seis cenários principais para os quais foram identificadas as implicações sobre as obras do TAV.

Para todos os cenários, os meios solo e água subterrânea foram considerados contaminados em função de ausência de dados que identifiquem com precisão qual o meio impactado e qual a extensão da contaminação.

Cenário 1: obras em superfície que incluem atividades apenas de aterro, sem intercepção das águas subterrâneas. As AC e/ou AP localizam-se na AID e, portanto, as fontes potenciais primárias e secundárias não interceptam o traçado. A única implicação identificada neste caso foi aquela correspondente à classe [1] da Tabela 1.

Cenário 2: obras em superfície que incluem atividades não só de aterro, mas também de corte. Nesse caso, foi considerada a intercepção das águas subterrâneas. As AC e/ou AP localizam-se na AID e, portanto, as fontes potenciais primárias e secundárias não interceptam o traçado. As implicações identificadas para esse cenário foram: [1], [3], [4] e [6] da Tabela 1.

Cenário 3: obras em superfície que incluem atividades apenas de aterro, sem intercepção das águas subterrâneas. As AC e/ou AP localizam-se na ADA e, portanto, as fontes potenciais primárias e secundárias interceptam o traçado. As implicações identificadas neste caso foram: [1], [2], [3] e [4] da Tabela 1.

Cenário 4: obras em superfície que incluem atividades de aterro e corte. Neste caso foi considerada a intercepção das águas subterrâneas. As AC e/ou AP localizam-se na ADA e, portanto, as fontes potenciais primárias e secundárias interceptam o traçado. As implicações identificadas para esse cenário foram: [1], [2], [3], [4], [5] e [6] da Tabela 1.

Cenário 5: nos trechos de obras em túnel, foi considerada a intercepção das águas subterrâneas. As AC e/ou AP não interceptam o traçado e, portanto, as fontes potenciais primárias e secundárias localizam-se a jusante ou a montante, em termos hidrogeológicos, do traçado. As implicações identificadas foram: [1], [3], [4] e [6] da Tabela 1.

Cenário 6: nos trechos de obras em túnel foi considerada a intercepção das águas subterrâneas. As AC e/ou AP interceptam o traçado e, portanto, as fontes potenciais primárias e secundárias localizam-se sobre o traçado. As implicações identificadas foram: [1], [2], [3], [4], [5] e [6] da Tabela 1.

Para cada um dos cenários 1 a 6 foram identificadas as possíveis implicações sobre a obra. A Tabela 1 apresenta a correspondência entre os códigos e as implicações sobre a obra ao longo do traçado do TAV.

\section{AÇÕES DE GERENCIAMENTO AMBIENTAL}

Considerando as características das áreas identificadas, dos seus potenciais impactos ambientais e riscos à saúde humana e das implicações sobre a obra, foram identificadas as seguintes ações ambientais para a implantação do TAV:

- Elaboração de planos de investigação para trechos de obra;

- Instalação de poços sentinelas, coleta de amostras e análises laboratoriais e

- Implementação de medidas de caráter institucional tais como: uso de equipamento de proteção individual (EPI), monitoramento de vapores orgânicos e disposição de solos contaminados.

A determinação das ações propostas foi fundamentada em procedimentos, normas e na legislação ambiental em vigor, nas informações e dados obtidos e nas premissas consideradas para a elaboração dos "cenários potencias de obra”. A estratégia de gerenciamento proposta deve ser implementada de forma progressiva, o que permitirá obter inicialmente uma caracterização completa das áreas cadastradas, seguida da revisão dos cenários potenciais de obra e das implicações por trecho e, por fim, a adoção das ações propostas.

\section{CONSIDERAÇÕES FINAIS}

O presente trabalho propõe uma contribuição metodológica para o gerenciamento ambiental de obras lineares que interceptam áreas contaminadas, como ferrovias de alta velocidade, com base no conhecimento prévio das áreas contaminadas, dos seus modelos conceituais de contaminação e do tipo de intervenção, utilizando-se de cenários potenciais de obra.

O estudo deste tema, no cenário nacional e internacional, é bastante recente, com regulamentação em processo de discussão e consolidação, sendo escassos os estudos que relacionam a temática do gerenciamento de áreas contaminadas ao planejamento e execução de obras lineares. De acordo com SANTOS (2012), de maneira geral as práticas de gerenciamento de áreas contaminadas em obras de metrôs em diversos países é feita por meio da implementação de ações de controle nos projeto, sem uma sistematização. 
Implantação de ferrovias de alta velocidade: contribuição metodológica para o gerenciamento ambiental de obras lineares em áreas contaminadas e potencialmente contaminadas

O método proposto permite a identificação das implicações sobre a obra e facilita a integração de ações dos especialistas das áreas de planejamento de transportes e da gestão ambiental, durante todas as fases de implantação do empreendimento, especialmente do modo ferroviário de alta velocidade para transporte de passageiros.

A utilização do método nos estudos ambientais para implantação do TAV permitiu, de forma inovadora e eficiente, a identificação das implicações sobre a obra e das ações ambientais para minimizar os impactos ambientais e eliminar os riscos potenciais à saúde humana dos trabalhadores da obra.

\section{REFERÊNCIAS}

ABNT (2013) ABNT - Associação Brasileira de Normas Técnicas (2013). NBR 16210 - Modelo conceitual no gerenciamento de áreas contaminadas - Procedimento. Rio de Janeiro.

ANTT (2012). Agência Nacional de Transportes Terrestres. Trem de alta velocidade - TAV Brasil. Disponível em www.antt.gov.br/index.php/content/view/5448/

Trem_de_Alta_Velocidade__TAV.html, acessado em 14. Dezembro, 2012.

Assembléia Legislativa do Estado de São Paulo. Lei Estadual $n^{\circ}$ 13.577, de 8 de julho de 2009. Dispõe sobre diretrizes e procedimentos para a proteção da qualidade do solo e gerenciamento de áreas contaminadas. São Paulo.

CETESB (2001). Companhia de Tecnologia de Saneamento Ambiental. Manual de Gerenciamento de Áreas Contaminadas.

CETESB (2007). Companhia Ambiental do Estado de São Paulo. Decisão de Diretoria $N^{\circ} 167 / 2007$. Dispõe sobre procedimentos para gerenciamento de áreas contaminadas. São Paulo.

CONAMA - Conselho Nacional de Meio Ambiente (2009) Resolução $n^{\circ} 420$ de 28 de Dezembro de 2009. Dispõe sobre critérios e valores orientadores de qualidade do solo quanto à presença de substâncias químicas e estabelece diretrizes para o gerenciamento ambiental de áreas contaminadas por essas substâncias em decorrência de atividades antrópicas. Brasília.

Lieggio Jr, M.; Filho, J. K. D. M.; Alves C. F. C.; Barbosa, A. O.; Cagnon, F. A. (2012). Implantação de ferrovias de alta velocidade e meio ambiente: Identificação e caracterização de áreas contaminadas. Revista ANTT, v. 4, n. 1, 90-110.

Mattiaso, D.P (2010). Nova Fase para Gestão de Solos Contaminados. Revista Meio Ambiente Subterrâneo, São Paulo, Ano 3, n. 14, p. 18-19.

PRIME (2008). Prime Engenharia. Estudos Ambientais de Alternativas para o Trem de Alta Velocidade (TAV) - Relatório Preliminar. Inter - American Development Bank / Prime Engenharia: São Paulo - SP.

REGEA (2012). Geologia e Estudos Ambientais. Caracterização de Áreas Potencialmente Contaminadas - Fase 1. REGEA, São Paulo - SP.

Sánchez, L. E. (1998). A desativação de empreendimentos industriais: um estudo sobre o passivo ambiental. $178 \mathrm{f}$. Tese (Livre-Docência) - Escola Politécnica, Universidade de São Paulo, São Paulo.
Santos, A. P. R. (2012) Diretrizes para minimização de interferências de áreas contaminadas nos cronogramas dos empreendimentos do metrô de São Paulo, Brasil. São Paulo, 2012. 99p.

USEPA (2001). United States of America - Environmental Protection Agency. Land Disposal Restriction. Reviewed August, 2001. Number EPA530-R-01-007. 119 p. 